\title{
Coronary artery and myocardial inflammatory reaction induced by intracoronary stent
}

\author{
Alterações inflamatórias das artérias coronárias e do miocárdio induzidas por stents coronários
}

\author{
Walter J. GOMES, Osvaldo GIANNOTTI FILHO, Roberto CATANI, Rodrigo P. PAEZ, Nelson A. HOSSNE \\ JR, Enio BUFFOLO.
}

\section{Abstract}

Background: Intra-coronary stents have been extensively employed in percutaneous coronary revascularization. However, despite breakthroughs and developments associated to this new technology, novel complications and findings have emerged compelling the cardiac surgeon to cope with this new scenario. The presence of an intra-coronary foreign body (stent) might induce an inflammatory reaction carrying functional and structural repercussions of the coronary artery and surrounding cardiac muscle.

Method: Patients, who had previously undergone stent implantation (6 to 18 months) and were submitted to coronary artery bypass surgery, had biopsies taken from the grafted coronary artery distal to the stent and from the adjacent muscle. The collected samples were processed and stained with hematoxylin-eosin and histologically studied.

Results: The histology of the coronary artery distal to the stent revealed chronic inflammatory processes and an intimal acute inflammatory infiltrate, with polymorphonuclear leukocytes even at long term follow-up, 12 months after stent implantation, disclosing an ongoing inflammatory process. The myocardium adjacent to the stent implantation site exhibited a significant chronic inflammatory infiltrate and fibrosis compatible with myocarditis.

Conclusion: The presence of an intra-coronary stent induces an acute and chronic inflammatory reaction, even over the long term, with involvement of the distal coronary artery and surrounding myocardium. Further studies are necessary to assess the inflammatory process extension and its consequences.

Key words: stent, coronary artery bypass grafting, inflammation
Resumo:

Objetivo: Stents intracoronários têm sido extensivamente utilizados na revascularização coronária percutânea. Entretanto, apesar dos avanços e desenvolvimento nessa área, novas complicação tem emergido obrigando o cirurgião cardíaco a enfrentar esta nova situação. A presença do stent poderia induzir reação inflamatória tipo corpo-estranho com repercussão funcional na artéria coronária e no músculo cardíaco.

Casuística e Método: Pacientes portadores de stents intracoronários e submetidos a cirurgia de revascularização miocárdica foram submetidos a biopsia da artéria coronária no local imediatamente distal ao stent e do músculo adjacente. Os materiais foram processados e estudados histologicamente.

Resultados: Os estudos histológicos mostraram intenso processo inflamatório agudo, com predomínio de leucócitos polimorfonucleares na íntima das artérias coronárias, mesmo em pacientes no seguimento tardio, evidenciando um processo inflamatório continuado. A análise do miocárdio adjacente ao local de implante exibiu também processo infiltrativo inflamatório, compatível com miocardite.

Conclusão: O uso de stents intracoronários desencadeia um processo inflamatório crônico que pode ser reagudizado, com envolvimento miocárdico e dos segmentos distais da artéria coronária. Estudos adicionais são necessários para avaliar a extensão do processo inflamatório e suas conseqüências.

Descritores: stent, cirurgia de revascularização miocárdica, inflamação.

Work performed in the Cardiovascular Surgery Department, Escola Paulista de Medicina - Federal University of São Paulo, São Paulo, Brazil.

Corresponding author

: Walter J. Gomes, Disciplina de Cirurgia Cardiovascular, Escola Paulista de Medicina - Universidade Federal de São Paulo - Rua

Botucatu 740 - CEP 04023-900 - São Paulo - SP.

Telefone 11-55764055. Fax: 55-11-55712719.

E-mail: wjgomes.dcir@epm.br 


\section{INTRODUCTION}

Coronary stents are extensively used for the treatment of coronary arterial disease [1]. In 2000, more than one million stents were implanted throughout the world and currently they are used in between 70 and $90 \%$ of percutaneous coronary intervention (PCI) cases. Although the initial results are considered good, the effects and consequences of the introduction of an intra-arterial foreign body have been studied little. It can induce an inflammatory reaction leading to functional and structural repercussions of the coronary artery and the myocardium.

Thus, this work was conceived to study the nature and involvement of the inflammatory process in the coronary arterial wall distal to the stent and in the adjacent cardiac muscle.

\section{METHOD}

\section{Patients}

Six patients submitted to coronary artery bypass grafting (CABG), who had previously implanted intra-coronary stents were studied. Indication for surgery was progressive coronary arterial disease and either total or partial obstruction of the stent. Four of the patients were male and two female, with ages ranging from 48 to 74 years. The period between the implantation of the stent and CABG varied from two weeks to 18 months. The arteries, which were previously treated with the stent, were the descending artery in five cases and the right coronary artery in one case.

The surgeries were elective in all cases except one, where the patient developed coronary thrombosis two weeks after stent implantation and was submitted to urgent surgery.

\section{Technique}

During CABG, the artery with the implanted stent, requiring surgical revascularization was opened longitudinally at approximately 10 to $20 \mathrm{~mm}$ distal of the site of the stent. The coronary arteriotomy performed was of 10 $\mathrm{mm}$ and a fusiform fragment of 5 to $7 \mathrm{~mm}$ length was removed (Figure 1). These small fragments were handled carefully to avoid damage to the structure of the wall. Subsequently a graft (either left mammary artery or saphenous vein) was anastomosed on this arteriotomy. In four patients a biopsy of the left ventricular myocardium adjacent to the stent implantation site was effected using a biopsy needle "Trucut" (Baxter Healthcare, Deerfield, IL).

The samples were fixed in $10 \%$ formaldehyde solution, embedded in paraffin and cut in $5 \mu \mathrm{m}$ sections. All the sections, coronary arteries and myocardium alike, were stained using hematoxylin-eosin. An experienced pathologist performed optical microscopy and the most representative images were chosen.

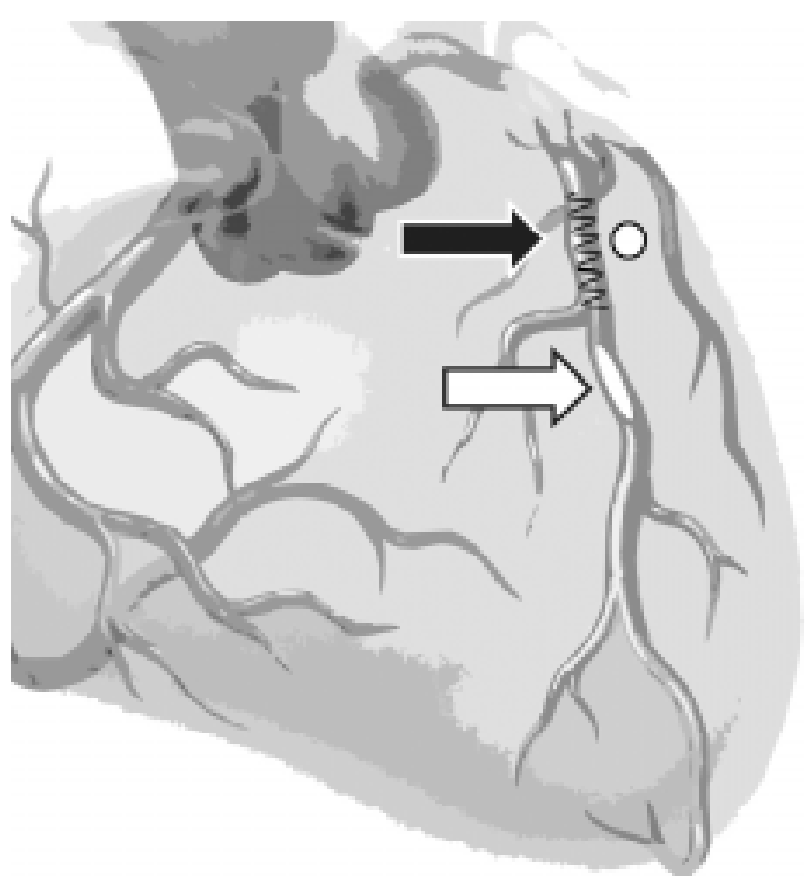

Figure 1. Coronary arterial biopsy site. Arrows: black = stent site $;$ white = Coronary arterial biopsy site circular = myocardial biopsy site.

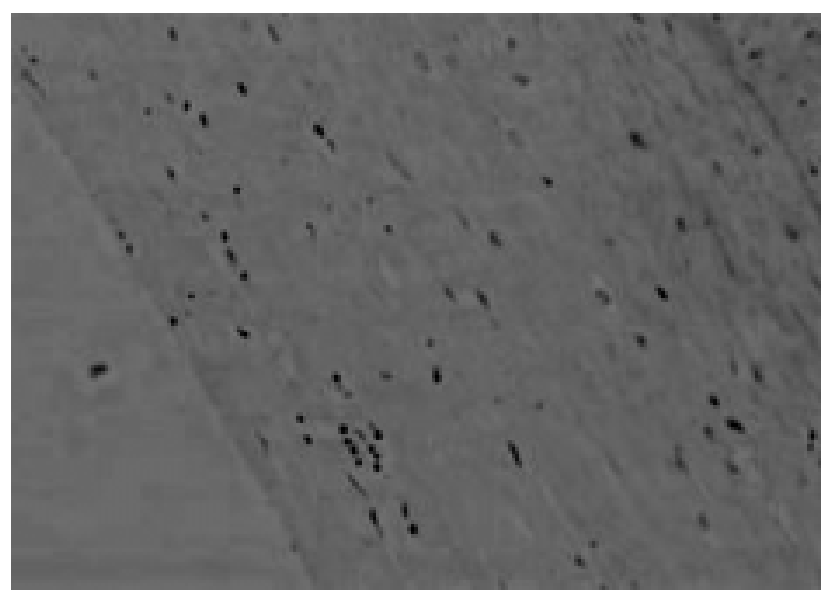

Figure 2. Microphotography of the coronary arterial wall. Slight inflammatory reaction with coronary wall showing leukocytic infiltration in the tunica intima and tunica media. (hematoxylineosin; 100X magnification).

\section{Results}

Analysis of the fragments of coronary arteries revealed an inflammatory process involving both tunica media and intima, varying from a slight to intense reaction. The inflammatory process with acute infiltration of polymorphonuclear leukocytes can be evidenced even in the long-term, 18 months after stent implantation, revealing an ongoing inflammatory process. Figure 2 shows a slight inflammatory process in a sample collected four weeks after sent implantation, with leukocytic infiltration of the tunica 


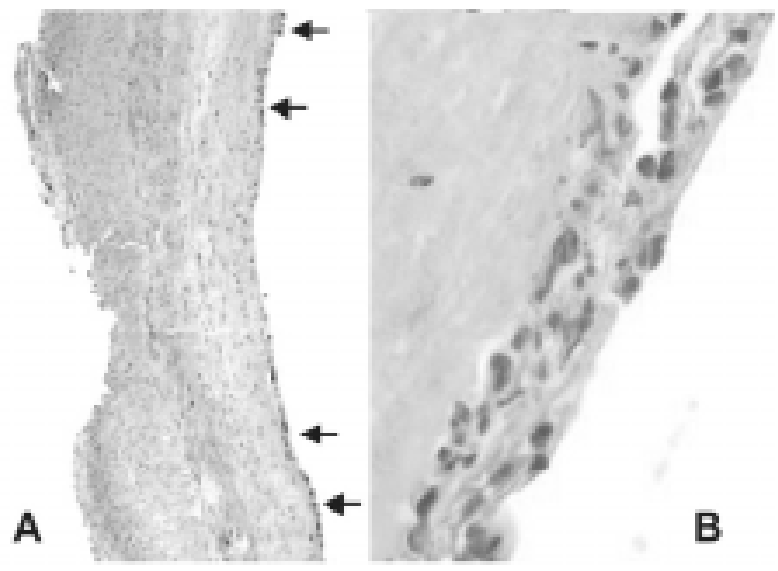

Figure 3. A. Microphotography of the coronary arterial wall. Moderate to intense inflammatory reaction with neutrophilic infiltration in the endothelial layer (arrows). Also thickening of the arterial walls and edema of the mid-tunic can be observed. (hematoxylin-eosin; 40X magnification). B. The same specimen magnified by $400 X$, highlighting the neutrophils infiltrating the endothelium, suggesting an acute reaction.

intima and media. Figure 3 demonstrates a moderate to intense inflammatory process in a specimen collected 18 months after stent insertion. It is possible to see neutrophils infiltrating the endothelium and revealing an acute inflammation. Also edema of the tunica elastica can be noted and thickening of the arterial wall. The myocardium adjacent to the stent insertion site exhibited acute and chronic inflammatory infiltration and also areas of necrosis. Figure 4 demonstrates an example of a significant worsening of a chronic inflammatory reaction accompanied by fibrosis, compatible with myocarditis, 12 months after stent implantation. Also it is possible to observe in this figure capillary neoformation, leukocyte infiltration, edema and congestion. Figure 5 evidences an example of myocardial structural degeneration and a necrotic process, revealing an acute reaction, 4 weeks after stent implantation.

A biopsy of the myocardium in the case of stent thrombosis presented an interesting finding, the myocardial capillaries were occluded by soft thrombosis (Figure 6).

\section{COMMENTS}

This study was planned after initial observations that, when operating on patients with coronary stents, it was noted that the coronary artery and the surrounding tissues were more inflamed, frail and bled at the slightest touch. Also it was observed that when operating on cardioplegic arrest patients, generally a hardening, similar to a granloma, was observed in the area around the implantation.

For a long time it has been recognized that a foreign body in the organism is capable of triggering a chronic inflammatory process leading to the formation of granulomas. The primary cells in granulomas of foreign
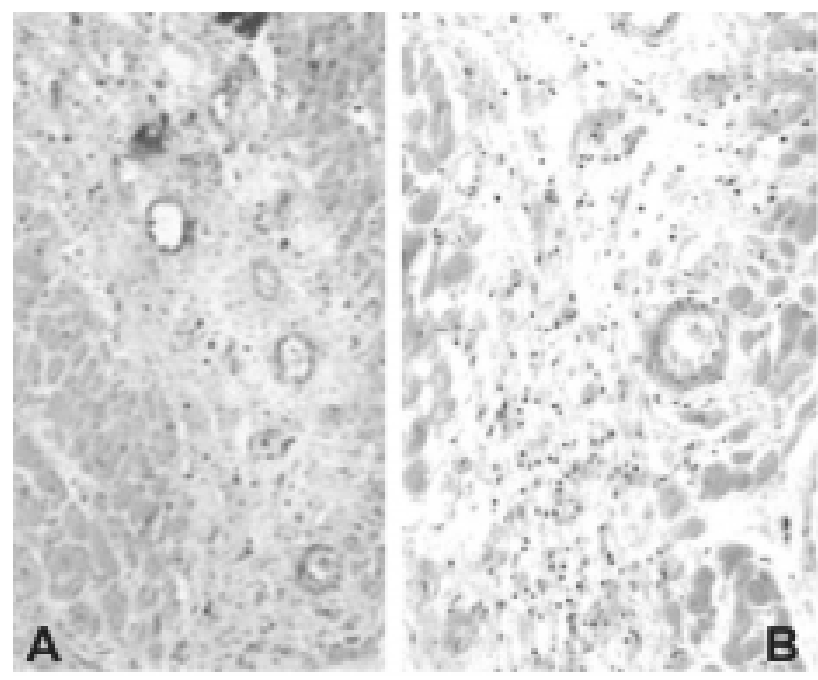

Figure 4. A. Microphotography of the myocardium adjacent to coronary artery exhibiting an important inflammatory infiltration and fibrosis. Also vascular neoformation, edema and congestion can be observed (hematoxylin-eosin; $40 X$ magnification). $B$. Magnification at 100X of the same specimen emphasizing the inflammatory infiltration.

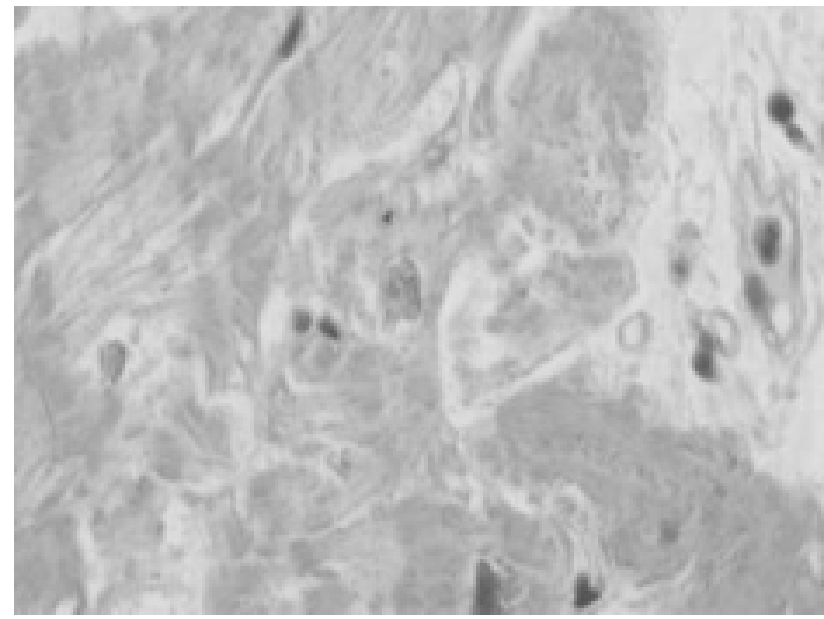

Figure 5. Microphotography of the peri-stent myocardium showing cardiac muscle degeneration and necrosis, denoting an acute process. (hematoxylin-eosin; 400X magnification).

bodies are macrophages containing a great number of phagocytic vacuoles with few secretary organelles [2]. Granulomas do not behave as static formations, but continually incorporate more inflammatory cells. Several cytokines have been identified as mediators involved in the formation and maintenance of these granulomas: IL-2, interferon â, TNF-á and IL-1 [3]. This response might be synergic with that observed in atherosclerotic plaque, where activated macrophages make up approximately $25 \%$ of the population of inflammatory cells [4]. As well as this, the density of macrophages in the lesion in question, can be considered as markers for the appearance of restenosis after PCI [5]. 


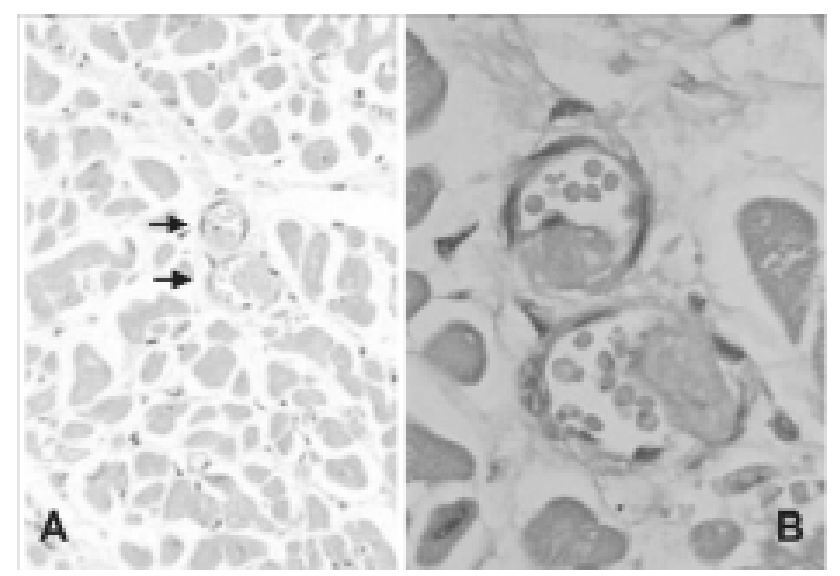

Figure 6. A. Microphotography of the myocardium adjacent to the coronary artery showing micro-thrombi occluding the myocardial capillaries. Also myocardial fibers without striations or nuclei, suggesting a process evolving to necrosis can be evidenced. (hematoxylin-eosin; 100X magnification). B. Magnification at $400 X$ of the same specimen detailing the occluded myocardial capillaries.

Coronary stent implantation seems to cause a more severe lesion [6,7] and a more intense inflammatory response inside the arterial wall than in other types of percutaneous interventions $[8,9]$. The arterial wall distension and the vascular lesion caused by the balloon in angioplasty and the placement of the stent, act as a potent stimulus for the proliferation of smooth muscle cells and neo-intimal hyperplasia $[10,11]$. Until now, the data of experimental and clinical trials suggest that the vascular lesion provoked by insufflation of the balloon may determine the cellular response $[12,13]$. However, the vascular lesion caused by the implantation of the coronary stent is more accentuated. The mesh of stents causes a very deep focal vascular trauma and the intensity and duration of the cellular proliferation exceeds that which is provoked by the lesion of a balloon catheter. These effects are increased by prolonged mechanical tension exerted by the stent on the coronary arterial wall. Other effects of residual permanence of a foreign body after PCI include chronic inflammation [14]. Recently other publications augmented the evidence that stents are associated with severe infiltration of inflammatory cells in the arterial walls $[8,9,15,16]$.

Farb et al. [16] demonstrated that soon after the insertion of the stent ( $<11$ days), plaques, fibrin and an infiltration of inflammatory cells were present in the coronary wall, mainly at the points of contact with the stent's mesh. Chronic inflammation was also observed adjacent to the mesh, principally 12 days after the implantation [16].

Another recent publication, investigating the liberation of pro-inflammatory cytokines long after coronary stent implantation confirmed our findings. In this work the serum levels of soluble receptors of interleukin-2 (sIL-2R) responsible for T-lymphocyte activation (cells-mediated immunity markers) were still high 4 months after stent implantation. The pro-inflammatory cytokines and the acute phase proteins were also precociously liberated into the peripheral circulation and the cell-mediated immunity persisted for at least 12 weeks after the implantation of the stent [17].

Apart from the direct inflammatory effect, embolization can play a fundamental role in the inflammatory process. Distal coronary embolization visible by coronary angiography is reported in $15 \%$ of patients submitted to stent implantation and this is associated with a worse prognosis [18]. This was confirmed in studies of subgroups in SYMPHONY and 2nd SYMPHONY clinical trails, where the incidence and clinical significance of the increase in cardiac troponin I (cTnI) after PCI was evaluated. Fortyeight percent of the patients had increased levels of cTnI and these were associated with a significant increase in the risk of mortality or infarction and worse clinical results in the first 90 days after intervention [19]. The incidence of troponin I liberation has been reported to be greater in patients treated with stents compared to those only treated by angioplasty $[19,20,21]$.

An important implication of the inflammatory reaction of the stent is related to the endothelium function. Caramori et al. studied patients after 6 months of coronary stent implantation with isolated lesions proximal to the anterior descending artery but without evidence of restenosis. The presence of severe coronary endothelium dysfunction was demonstrated even over the long term, mainly when compared with balloon angioplasty and atherectomy [22]. This suggests that stents can cause a significant acceleration of the progression of coronary arterial disease. Also there may be systemic implications. Wu et al. [23] investigated the systemic endothelium function of arteries in the forearm of patients after stent implantation. In patients with angiographic restenosis of the stent, the active hyperemia of the forearm was worse and this was associated with the release of endothelin-1 which is liberated by the endothelium [23] and increases in the coronary circulation immediately after PCI [24]. Endothelin-1 acts as a potent vasoconstrictor and at the same time as a stimulant for the proliferation of the smooth muscle cells of the vessels [25].

The finding in the case of stent thrombosis in this work, where the myocardial capillaries adjacent to the site of the stent were occluded by soft thrombosis, gives us an interesting inference. Urgent surgical revascularization in the case of complications due to stents may not only be ineffective but even deleterious, as the microcirculation is already compromised and reperfusion inhibited. Our findings could also have implications in respect to the accelerated progression of atherosclerosis in the coronary arteries submitted to stent implantation.

Although this study focussed on complicated stent cases, the majority being restenosis, this might be 
representative of a significant percentage of the coronary arteries with stents, as the rate of stent restenosis has been reported as higher than 36\% (SIRIUS) or even higher in non-selected patients. Until now, nothing has been reported about myocardial inflammatory compromise due to a peristent reaction. Further studies will be necessary to characterize the extension and the consequences of this process for coronary arteries and the myocardium.

In conclusion, the presence of intra-coronary stents induces acute and chronic inflammatory reactions, even over the long-term post-implantation period of stents, with involvement of the distal coronary artery and the adjacent myocardium. Additional studies will be necessary to elucidate the extension of the inflammatory process and its consequences.

\section{Explicatory note}

The term Intraluminary sustained endoprosthesis (ISE) has been proposed to substitute the word stent due to its greater functional significance and because it is selfexplanatory. We recommend that the term should be used as an alternative to the name stent.

\section{BIBLIOGRAPHIC REFERENCES}

1. Sigwart U, Puel J, Mirkovitch V, Joffre F, Kappenberger L. Intravascular stents to prevent occlusion and restenosis after transluminal angioplasty. N Engl J Med 1987; 316:701 6.

2. Elias PM, Epstein WL. Ultrastructural observations on experimentally induced foreign-body and organized epithelioidcell granulomas in man. Am J Pathol 1968;52:1207-11.

3. Soler P, Bernaudin JF. Physiologie des granulomes. Rev Pneumol Clin 1993;49;257-61.

4. Kern MJ, Meier B. Evaluation of the culprit plaque and the physiological significance of coronary atherosclerotic narrowings. Circulation 2001;103:3142-9.

5. Moreno PR, Bernardi VH, Lopez-Cuellar J, et al. Macrophage infiltration predicts restenosis after coronary intervention in patients with unstable angina. Circulation 1996;94:3098-102.
6. Hoffman R, Mintz GS, Dussaillant R et al. Chronic arterial response to stent implantation: a serial intravascular ultrasound analysis of Palmaz-Shatz stents in native coronary artery heart disease. J Am Coll Cardiol 1996;28:1134-9.

7. Hanke H, Kamenz J, Hassenstein S et al. Prolonged proliferative response of smooth muscle cells after experimental intravascular stenting. Eur Heart J 1995;6:785-93.

8. Kollum M, Kaiser S, Kinscherf R, Metz J, Kubler W, Hehrlein C. Apoptosis after stent implantation compared with balloon angioplasty in rabbits: role of macrophages. Arterioscler Thromb Vasc Biol 1997;17:2383-8.

9. Hofma SH, Whelan DM, van Beusekom HM, Verdouw PD, van der Giessen WJ. Increasing arterial wall injury after lonterm implantation of two types of stent in a porcine coronary model. Eur Heart J 1998;19:601-9.

10. Karas SP, Gravanis MB, Santoian EC, Robinson KA, Andernerg KA, King SB III. Coronary intimal proliferation after baloon injury and stenting in swine: an animal model of restenosis. J Am Coll Cardiol 1992;20:467-74.

11. Rogers C. Karnovsky MJ, Edelman ER. Inhibition of experimental neointimal hyperplasia and thrombosis depends on the type of vascular injury and the site of drug administration. Circulation 1993;88:1215-21.

12. Kuntz RE, Safian RD, Levine MJ, Reis GJ, Diver DJ, Baim DS Novel approach to the analysis of restenosis after the use of three new coronary devices. J Am Coll Cardiol 1992:19:1493-9.

13. Schwartz RS, Huber KC, Murphy JG, et al. Restenosis and proportional neo intimal response to coronary artery injury. J Am Coll Cardiol 1991:19:267-74.

14. Orford JL, Selwyn AP, Ganz P, Popma JJ, Rogers C. The comparative pathobiology of atherosclerosis and restenosis. Am J Cardiol 2000;86(suppl):6H-11H.

15. van Beusekom HMM, Whelan DM, Hofma SH, et al. Long-term endothelial dysfunction is more pronounced after stenting than after balloon angioplasty in porcine coronary arteries. J Am Coll Cardiol 1998;32:1109-17.

16. Farb A, Sangiorgi G, Carter AJ, et al. Pathology of acute and chronic coronary stenting in humans. Circulation 1999;99:44-52.

17. Caixeta AM, Brito Jr FS, Serrano CV, et al. Cytokines and inflammatory markers are released early after coronary stenting and are related to 6-month clinical outcome (Abstract). Eur Heart J 2002;4(suppl):555.

18. Henriques JPS, Zijlstra F, Ottervanger JP, et al. Incidence and clinical significance of distal embolization during primary angioplasty for acute myocardial infarction. Eur Heart $\mathbf{J}$ 2002;23:1112-7. 
19. Cantor WJ, Newby LK, Christenson RH, et al. Prognostic significance of elevated troponin I after percutaneous coronary intervention. J Am Coll Cardol 2002;39:1738-44.

20. Shyu KG, Kuan PL, Cheng JJ, Hung CR. Cardiac troponin T, creatine kinase, and its isoform release after successful percutaneous transluminal angioplasty with or without stenting. Am Heart $\mathbf{J}$ 1998;135:862-7.

21. La Vecchia L, Bedogni F, Finocchi G, et al. Troponin T, troponin I and creatine kinase-MB mass after elective coronary stenting. Coron Artery Dis 1996;7:535-40.

22. Caramori PRA, Lima VC, Seidelin PH, Newton GE, Parker JD, Adelman AG. Long-term endothelial dysfunction after coronary artery stenting. J Am Coll Cardiol 1999;34:1675-9.
23. Wu TC, Chen $\mathrm{YH}$, Chen JW, et al. Impaired forearm reactive hyperemia is related to late restenosis after coronary stenting. Am J Cardiol 2000;85:1071-6.

24. Kruger D, Giannitsis E, Sheikhzadeh A, Stierle U. Cardiac release and kinetics of endothelin after uncomplicated percutaneous transluminal coronary angioplasty. Am J Cardiol 1998;81:1421-6.

25. Hafizi S, Allen SP, Goodwin AT, Chester AH, Yacoub MH. Endothelin-1 stimulates proliferation of human coronary smooth muscle cells via the ET(A) receptor and is co-mitogenic with growth factors. Atherosclerosis 1999;146:351-9. 